\title{
What Measure of Lower Extremity Muscle Strength Best Explains Walking Independence?
}

J. Phys. Ther. Sci.

13: $1-3,2001$

\author{
RICHARD W. BOHANNON ${ }^{1,2)}$, OLA ERIKSRUD ${ }^{1)}$ \\ ${ }^{1)}$ Department of Physical Therapy, School of Allied Health U-2101, University of Connecticut, \\ Storrs, CT 06269-2101, USA. TEL +18604861588 FAX +1 860-486-0048 \\ E-mailbohannon@neca.com \\ ${ }^{2)}$ Institute of Outcomes Research and Evaluation, Hartford Hospital, Hartford, CT
}

\begin{abstract}
This study was conducted to determine if any one strength measure or combination of strength measures provided an explanation of ambulatory independence among 107 acute rehabilitation patients. This was a retrospective, descriptive, and correlational study where ambulatory function was quantified using the Functional Independence Measure (FIM). Lower extremity strength was quantified by sit to stand performance, and knee extension force measured by manual muscle testing and hand held dynamometry. Descriptive, correlational, and multiple regression statistical analysis were used. Correlation coefficients between ambulatory independence and the different strength measures ranged from .414 to .585 . Sit to stand had the highest correlation coefficient with ambulatory independence $(r=.585)$. However a combination of sit to stand performance and total knee extension force offered the best explanation of ambulatory independence ( $\mathrm{r}=.617)$. A combination of functional and instrumental strength testing is therefore indicated in the prediction of ambulatory performance of patients in acute rehabilitation.
\end{abstract}

Key words: Aging, Sit to stand, Adaptive equipment, Muscle strength.

(This article was submitted Mar. 10, 2000, and was accepted Jun. 20, 2000)

\section{INTRODUCTION}

For at least some patients participating in rehabilitation, walking is the chief goal ${ }^{1)}$. Of the various aspects of walking, independence appears to be particularly important ${ }^{2}$. Clinicians seeking to improve the ambulatory independence of their patients need to know which impairments are relevant to the patients' ambulation. Muscle strength has been established incontrovertibly as such an impairment ${ }^{3-8)}$. Whether any particular measure of strength offers a better explanation of walking independence remains to be established. The purpose of this study therefore was to determine which of four measures of lower extremity muscle strength offered the best explanation of ambulatory independence among acute rehabilitation patients.

\section{METHODS}

This was a retrospective study involving the secondary analysis of a database including 107 acute rehabilitation patients. The study was approved by the Institutional Review Committee of Hartford Hospital.

Subjects participating in this study represented consecutive patients admitted to an acute rehabilitation unit who were treated by the senior author. All could follow verbal instructions. Excluded were patients who had amputations or fractures of the lower extremity or other conditions 
limiting weight-bearing or precluding strength testing. Fifty-five were men and 52 were women. Their mean ( \pm standard deviation) age was $62.1 \pm$ 16.4 years.

Walking independence was quantified using the seven level Functional Independence Measure (FIM) in which 1 represents total dependence and 7 indicates complete independence over 150 feet. Three measures described in a previous study of home care patients were used in this study; that is, manual muscle testing, hand-held dynamometry, and sit to stands. Manual muscle testing was conducted as described by Hislop and Montgomery, except grades were assigned on the basis of an expansion of the Medical Research Council (0-5 system). Scores of $0-12$ were assigned as follows: $0=0,1=1,1+=2,2-=3,2=4,2+=5,3-=6,3=7,3+=8$, $4-=9,4=10,4+=11,5=12$. These scores were added to obtain a total manual muscle test grade for the two extremities. An Ametek Cadet digital handheld dynamometer was used to measure the isometric knee extension strength of patients while they sat upright with their knees at about 90 degrees. The dynamometer was held stationary and perpendicular to the leg, just proximal to the malleoli during testing. The maximum force during the three to four second effort was recorded in Newtons; this force was then normalized against (expressed as a percentage of) body weight. These scores were added to obtain total values for the lower extremities. Sit to stands were performed from a $45-48 \mathrm{~cm}$ high armless chair with a firm seat. Patients were described as able without hands $($ score $=2)$, requiring hands $($ score $=1)$, or unable (score $=0$ ).

The Systal statistical package (version 8.0) was used for all analyses. Following the calculation of descriptive statistics, Spearman and Pearson correlations were used to establish the relationship between the muscle strength variables and gait independence. Thereafter, multiple regression analysis was employed to determine whether any set of strength variables was better than any individual strength variable at explaining walking independence.

\section{RESULTS}

The walking FIM scores of the patients had a median of 4 and ranged from 1 to 7 . Specifically, the number $(\%)$ of patients with each FIM score was: FIM $1=27(25.2 \%)$, FIM $2=22(20.6 \%)$, FIM $3=2(1.9 \%)$, FIM $4=22(20.6 \%)$, FIM $5=21$ $(19.6 \%)$, FIM $6=4(3.7 \%)$, and FIM $7=9(8.4 \%)$. The Table 1 presents the descriptive statistics for the strength variables and the correlations between the variables and walking independence. The correlations ranged form .414 to .585 and were all significant at $\mathrm{p}<.001$. Sit to stand was correlated most strongly with walking independence $(\mathrm{r}=.576$, $\left.\mathrm{r}_{\mathrm{s}}=.585\right)$. Of the other strength variables, those involving the sum of both lower extremities (nondominant + dominant) had higher correlations with walking independence than either lower

Table 1. Summary of Lower Extremity Strength Measures and Their Correlations with Walking Independence

\begin{tabular}{lrrrrrrr}
\hline \multicolumn{1}{c}{ Strength measures* } & \multicolumn{3}{c}{ Descriptive statistics } & & \multicolumn{2}{c}{ Correlations** } \\
\cline { 2 - 5 } \cline { 5 - 6 } & Mean & Median & SD & Range & & Spearman & Pearson \\
\hline Knee Extension: ND (MMT) & 9.7 & 11.0 & 2.6 & $1-12$ & & .485 & .440 \\
Knee Extension: D (MMT) & 9.7 & 11.0 & 2.7 & $0-12$ & & .449 & .414 \\
Knee Extension: ND + D (MMT) & 19.4 & 21.0 & 4.4 & $10-24$ & & .553 & .514 \\
Knee Extension: ND (HHD) & 151.3 & 128.9 & 101.4 & $0-448.2$ & & .483 & .467 \\
Knee Extension: D (HHD) & 150.7 & 137.9 & 94.2 & $0-422.6$ & & .491 & .485 \\
Knee Extension: ND + D (HHD) & 302.9 & 284.7 & 171.2 & $50.7-800.7$ & & .533 & .546 \\
Knee Extension: ND (HHD\%) & 20.6 & 17.6 & 13.2 & $0-62.5$ & & .495 & .488 \\
Knee Extension: D (HHD\%) & 20.9 & 17.5 & 12.8 & $0-56.6$ & & .459 & .450 \\
Knee Extension: ND + D (HHD\%) & 41.6 & 35.2 & 23.0 & $6.1-113.0$ & & .524 & .542 \\
Sit to Stand & 1.1 & 1.0 & .9 & $0-2$ & & .585 & .576 \\
\hline
\end{tabular}

*ND= nondominant side, $\mathrm{D}=$ dominant side, $\mathrm{ND}+\mathrm{D}=$ sum of nondominant and dominant side; MMT=manual muscle test (ordinal score of 0-12); HHD=hand-held dynamometry (force in Newtons); HHD\%=hand-held dynamometry (force as a percentage of body weight), Sit to Stand $(2=$ able without hands, $1=$ able with hands, $0=$ unable with hands). **All correlations are significant at $\mathrm{p}<.001$. 
extremity alone. Multiple regression demonstrated that a combination of two lower extremity variables, sit to stand and total knee extension force in Newtons, had a multiple correlation of .617 with walking independence.

\section{DISCUSSION}

Like many previous studies ${ }^{3-8)}$, this investigation showed that lower extremity muscle strength is correlated with gait performance. Specifically, strength measures focused on or involving knee extension are correlated with walking independence. Although dynamometry is clearly superior to manual muscle testing for documenting impairments and changes in muscle strength, dynamometry was not consistently better at predicting walking independence. If the clinician is seeking a simple measure to explain walking independence, the sit to stand test may be best. Expanding the test to include the counting or timing of sit to stand repetitions, as is sometimes done ${ }^{6,10-12)}$, may expand the explanatory power of the test. Another test (total knee extension force measured by dynamometry) added to the explanation of walking independence provided by the sit to stand test. This finding supports the inclusion of instrumented tests even when a simple observational test (sit to stand) is itself correlated significantly with a patient valued variable such as walking independence.

\section{REFERENCES}

1) Bohannon RW, Andrews AW, Smith MB: Rehabilitation goals of patients with hemiplegia. 1988, Int J Rehabil Res 11: 181-182.

2) Bohannon RW, Horton MG, Wikholm JB: Importance of four variables of walking to patients with stroke. 1991, Int J Rehabil Res 14: 246-250.

3) Buchner DM, Larson EB, Wagner EH, et al.: Evidence for non-linear relationship between leg strength and gait speed. 1996, Age Ageing 25: 386-391.

4) Cunningham DA, Paterson DH, Hilmann JE, et al.: Determinants of independence in the elderly. 1993, Can J Appl Physiol 18: 243-254.

5) Waters RL, Yakura JS, Adkins R, et al.: Determinants of gait performance following spinal cord injury. 1989, Arch Phys Med Rehabil 70: 811-818.

6) Bohannon RW, Smith J, Hull D, et al.: Deficits in lower extremity muscle and gait performance among renal transplant candidates. 1995, Arch Phys Med Rehabil 76: 547-551.

7) Nakamura R, Hosokawa T, Tsuji I: Relationship of muscle strength for knee extension to walking capacity in patients with spastic hemiparesis. 1985, Tohoku J Exp Med 145: 335-340.

8) Bohannon RW: Manual muscle test scores alone provide a limited indication of the functional independence of home care patients. 1999, Int J Rehabil Res 22: 151-152.

9) Guide for the Uniform Data Set for Medical Rehabilitation (version 5.0). State University of New York at Buffalo, 1996, Buffalo, NY.

10) Bohannon RW: Alternatives for measuring knee extension strength of the elderly at home. 1998, Clin Rehabil 12: 434-440.

11) Csuka M, McCarty JD: Simple method for measurement of lower extremity muscle strength. 1985, Am J Med 78: 77-81.

12) Jones CJ, Rikli RE, Beam WC: A 30-s chair-stand test as a measure of lower body strength in communityresiding older adults. 1999, Res Quart Exerc Sci 70: 113-119. 